\title{
Analysis of Ausubel Auctions by Means of Evolutionary Computation
}

\author{
Asunción Mochón \\ $\mathrm{P}^{\circ}$ Senda del Rey, 11. 28040 Madrid. Spain \\ Facultad de CC Económicas y Empresariales \\ Department of Applied Economics, UNED \\ amochon@cee.uned.es \\ Yago Sáez \\ Av. Universidad 30 - 28911, Leganés, Madrid. Spain \\ Department of Artificial Intelligence, University \\ Carlos III of Madrid \\ yago.saez@uc3m.es
}

\begin{abstract}
The increasing use of auctions has led to a growing interest in the subject. A recent method used for carrying out examinations on auctions has been the design of computational simulations. The aim of this paper is to develop a genetic algorithm to find bidders' optimal strategies for a specific dynamic multi-unit auction, The algorithm provides the bidding strategy (defined as the action to be taken under different auction conditions) that maximizes the bidder's payoff. The algorithm is tested under several experimental environments, number of bidders and quantity of lots auctioned. The results suggest that the approach leads to strategies that outperform canonical strategies ${ }^{1}$.
\end{abstract}

\section{Introduction}

Nowadays auctions have been extensively used as selling mechanism in different markets around the world. The items or lots auctioned range from the wide variety of things being offered on Internet market-places like eBay; to the government auctions of spectrum rights (Klemperer, 1999), treasury bill, electricity, emissions permits; or the auctions of art, financial assets, agricultural goods, etc. As a result of these activities, auction theory and experimental examinations of these theories are of growing interest. It is very difficult to list the numerous papers on auctions but some references could be: McAfee and Mc Millan (1987); Laffont (1997); Kagel and Roth (1995); Klemperer (2000a); Klemperer (200b); Krishna (2002); Klemperer (2003); Milgrom (2004); etc.

A recent method used for analysing strategies on auctions is by means of systems of Artificial Adaptive Agents (AAA). The analysis of these systems gives us new approaches to the understanding of the economic and social behaviour of auctions. In this way, the use of machine learning systems could help in the finding of optimal strategies or in the evaluation, from different

\footnotetext{
${ }^{1}$ This article has been financed by the Spanish founded research MCyT project TRACER, Ref: TIC2002-04498-C05-04
}

\author{
David Quintana \\ Av. Universidad 30 - 28911, Leganés, Madrid. Spain \\ Department of Artificial Intelligence, University \\ Carlos III of Madrid \\ david.quintana@uc3m.es \\ Pedro Isasi \\ Av. Universidad 30 - 28911, Leganés, Madrid. Spain \\ Department of Artificial Intelligence, University \\ Carlos III of Madrid \\ pedro.isasi@uc3m.es
}

points of view, of the auction itself with respect to other possible auctions. In this context, Genetic Algorithms (GAs) are a good learning method. The first works using a genetic metaphor as computing systems were done by Fraser (1957) and Bremermann (1962). Afterwards, the GAs was formally introduced by Holland (1975) as a computational paradigm. The GAs have been applied to describe the learning behaviour of agents in various economics models (Miller, 1986; Arifovic, 1994; Dawid and Kopel, 1998; Arifovic, 1995; Arifovic, 1996; Arifovic and Gencay, 2000; Dawid, 1996; Axelrod, 1987; Miller, 1996; Routledge, 1995; etc).

Moreover, during the last years, GAs are being used in researches that include auctions. For instance Andreoni and Miller (1995) created and analysed a GA model to capture the bidding patterns evident among human subjects in experimental auctions. These authors compared the different results for first and second price auctions formats. Dawid (1999) modelled a twopopulation GA to study the learning behaviour of buyers and sellers in a sealed bid double auction. Numnonda and Annakkage (1999) proposed the application of a GA to solve the optimal power dispatch problem for a multinode electricity auction market to maximise the total participants' benefit at all nodes in the system. Wen and David (2001) addressed the problem of building optimal bidding strategies for competitive suppliers in a day-ahead energy market using a GA method. Anthony and Jennings $(2002,2003)$ employed a GA model to search for effective strategies with multiple auctions formats (English, Dutch and Vickrey). Cliff (2003) described the use of a GA to find optimal parameter-values for trading agents that operate in virtual online auction "emarketplaces", where the rules of those marketplaces are also under simultaneous control of the GA.

In this paper we are going to focus on a particular specification of a multiple-object ascending-clock auction develop by Ausubel $(1997,2004)$, which is usually refereed as the Ausubel auction. In this auction, with private values and diminishing marginal utilities, Sincere Bidding (SB) by every bidder constitutes an equilibrium. Some other authors have studied this auction format (Bikhchandani and Ostroy, 2005) and it has been frequently compare with other multi-unit auctions 
(Manelli, Sefton \& Wilner, 2000; Kagel, Kinross \& Levin, 2004; Kagel, Ye \& Pevnitska, 2004; Sunnevag, 2001.

The present paper reports a computational experiment comparing bidders' payoff for the Ausubel auction with dropout information. Our aim is to use GAs to find whether a canonical behaviour, SB, can be outperformed, form the bidder point of view, in some specific conditions. The work also tries to find out whether better strategies can be achieved automatically, by means of GAs.

The remainder of the article is structured in the following manner.

A definition of the auction model selected and the equilibrium bidding strategies are given in section 2 . In section 3 we described the experimental environment, the fundamentals of the bidding algorithm and the auction conditions that affect its performance. Section 4 evaluates the experimental results in several environments by comparing the bidders' payoff with the GA and SB strategy. We also address the question of what is the optimal bidding strategy that the GA propose that outperforms SB. To that end we have analysed deeply the bidders behaviour in six different experiments. In section 5 we present our conclusions and future work.

\section{The Ausubel Auction format}

In multiple-object environments, where individual bidders may demand more than one homogeneous items, the seller must choose among a wide variety of auction formats. This paper focuses on a particular specification of rules for what might be referred generically as an "ascending-clock auction". In the standard ascendingclock auction, where demands are required to be non incremental in price, the auctioneer employs a price "clock" stars at zero (or at a low price) and increases continuously thereafter. For each price, $p$, each bidder $i$ simultaneously indicates the quantity $q_{i}(p)$ he desires. When the price $p^{*}$ is reached, such that aggregate demand no longer exceeds supply, or until the exogenous ending time is reached, whichever occurs sooner, the auction is over. Each bidder $i$ is then assigned the quantity $q_{i}\left(p^{*}\right)$ and is charged a unit price of $p^{*}$.

The description of the alternative ascending-bid auction developed by Ausubel $(1997,2004)$ coincides with this auction format where bidders choose what price to drop out of the bidding, with dropping out being irrevocable. What is not specified however are the payments owed to each of the winners. As we have mentioned, when the auction is over each bidder $i$ is assigned the quantity $q_{i}\left(p^{*}\right)$ but is charged the standing prices at which the respective objects were "clinched". With $M$ object for sale at a price $p^{0}$, bidder $i$ clinches an object when the aggregate demand of all other bidders dropped, at least, from $M$ to $M-1$ but bidder $i$ still demands two units or more. In this situation bidder $i$ is guaranteed at least an object no matter how the auction proceeds. In this way the auction sequentially implements the Vickrey rule that each bidder pays the amount of the $k$ th highest rejected bid, other than his own, for the $k$ th object won.

There are two variants to the Ausubel auction: with and without dropout information. In the first one, dropout prices are announced as they occur, along with announcements of items earned (or clinched) and prices paid, as the auction proceeds. In the second one, winners and prices paid are not announced until the auction has ended.

For a better understanding of the allocation and payment rule of this mechanism, table 1 includes an example of the Ausubel auction where we suppose that there are four identical objects to sell, $M=4$. There are three bidders, $n=3$, and their marginal values are given as follows: Bidder A: $v_{A, 1}=40, v_{A, 2}=35, v_{A, 3}=30, v_{A, 4}=20$; Bidder B: $v_{B, 1}=40, v_{B, 2}=20, v_{B, 3}=15, v_{B, 4}=10$; Bidder C: $v_{C, 1}=25, v_{C, 2}=15, v_{C, 3}=10, v_{C, 4}=5$. Theses are marginal values for a first, second, third and fourth object, respectively.

\begin{tabular}{|c|c|c|c|c|c|}
\hline \multirow[t]{2}{*}{$\begin{array}{c}\text { Price } \\
(p)\end{array}$} & \multicolumn{3}{|c|}{$\begin{array}{c}\text { Quantities } \\
\text { demanded } \\
\text { by bidders } \\
\left(q_{i}\right)\end{array}$} & \multirow[t]{2}{*}{$\begin{array}{l}\text { Aggregate } \\
\text { demand } \\
\left(Q^{l}\right)\end{array}$} & \multirow[t]{2}{*}{ Clinching process } \\
\hline & $\mathrm{A}$ & B & $\mathrm{C}$ & & \\
\hline 0 & 4 & 4 & 4 & 12 & \\
\hline 5 & 4 & 4 & 3 & 11 & \\
\hline 10 & 4 & 3 & 2 & 9 & \\
\hline 15 & 4 & 2 & 1 & 7 & A "clinches" \\
\hline 20 & 3 & 1 & 1 & 5 & A "clinches" \\
\hline 25 & 3 & 1 & 0 & 4 & A \& B "clinches" \\
\hline
\end{tabular}

We assume that each bidder is going to bid according to their real values (sincere bidding). This means that bidders demand objects as long as their values are lower than the standing price. Therefore, at the initial price, $p=0$, the aggregate demand is 12 , which is bigger than the available supply, 4 , so the auction must proceed further. The auctioneer begins to continuously increment the clock and price and bidders submits their demands. The first important change occurs when the price reaches 15 . The aggregate demand at this price is 7 and the supply is 4 . Bidder A has now mathematically guaranteed himself at least one object as the aggregate demand of all competitors other than bidder A has dropped to 3. Bidder $\mathrm{A}$ has clinched winning an object. The auction ends when the price attains a level of 25 and bidder $\mathrm{C}$ drops out of the auction reducing the aggregate demand to just 4 , thus equating demand with supply. With this last round the final outcome of the auction is that bidder A wins three objects for 15,20 and 25 each and bidder B wins an object for 25 .

To be able to define the auction outcome, we first make a basic specification of the model from the formulation of Ausubel (1997), we consider all variables discrete. In each auction the seller offers $M$ number of indivisible units of a homogeneous good to $n$ number of bidders, where $n \geq M$. Each bidder $i$ obtains a marginal 
value of $v_{i, k}$ for the $k$ th unit of the good, for $k=1, \ldots, M$. Thus if bidder $i$ gets $q_{i}$ units of the good for a total payment of $P_{i}$, he obtains a payoff of:

$$
\sum_{k=1}^{q_{i}} V_{i, k}-P_{i}, \text { for } i=1, \ldots, n \text { and } q_{i}=1, \ldots, M
$$

All bidders are assumed to exhibit (weakly) diminishing marginal values, i.e., $v_{i, k} \geq v_{i, k+1} \geq 0$, for all $i=1, \ldots, n$ and $k=1, \ldots, M-1$ which are privately observed by the respective bidders, making this game of incomplete information. The estimation of the own value made by bidder $i$ is not affected by bidder $j$ 's valuation. As we will explain in the next section, bidders marginal values are generated randomly form an uniform distribution and are statistically independent of each other for $i \neq j$.

In our model we assume that all bidders have full bid information. This means that bidders have the complete history of all bids made by all bidders in the auction. This specification of the Ausubel auction with dropout information is sometimes refereed as the Ausubel-Plus auction (Kagel, Kinross and Levin, 2003).

For any round $l$, the aggregate demand by all bidders is $Q^{l}=\sum_{i} q_{i}^{l}$. Hence, the cumulative vector of quantities $C^{l}$ clinched at prices up to $p^{l}$ is define by equation (2)

$$
C_{i}^{l}=\max \left\{0, M-\sum_{j \neq i} q_{j}^{l}\right\}, \text { for } l=0, \ldots L-1 \text { and } i=1 . . n
$$

Given the individual quantities clinched at price $p^{l}$ by setting $c_{i}^{0}=C_{i}^{0}$ defined as follows:

$c_{i}^{l}=C_{i}^{l}-C_{i}^{l-1}$, for $l=0, \ldots, L-1$ and $i=1, \ldots, n$

The auction outcome associated with any final history $l=L$ is define in equations (4) and (5).

$$
\begin{aligned}
& \text { Allocation: } q_{i}^{*}=C_{i}^{L}, \text { for } i=1, \ldots, n \\
& \text { Payment: } P_{i}^{*}=\sum_{l=0}^{L} p^{l} c_{i}^{l}, \text { for } i=1, \ldots, n
\end{aligned}
$$

Ausubel (2004) demonstrated that in this auction format with pure private values, SB by every bidder is an ex post perfect equilibrium yielding to an efficient outcome. Notwithstanding, SB is not the unique equilibrium. In the experiment carried out by Kagel, Kinross and Levin (2004) with independent private values, behaviour in the Ausubel auction with dropout information comes significantly closer to SB.

In our model all but one of the bidders have a fixed bidding strategy: SB. There is only one bidder whose strategy depends on the process of the auction. This single bidder evolves according to a GA that learns the best strategy to implement from one auction to another and that indicates how the bidder should bid according to its results.

As price goes up and demanded quantities go down, it is possible that, for a certain increase of price, the supply is not covered at the final price $\left(p^{L}\right)$. In these circumstances the following rationing rule is introduced.
We turn to the previous price $\left(p^{L-1}\right)$ and allocate all the demanded units to the bidders. We then calculate the excess demand $\left(Q^{L-1}-M\right)$ and, beginning with the bidder who has the highest demanded quantity not clinched $q_{i}^{L-1}-C_{i}^{l-1}$, start to remove one unit from each bidder until the total demand equals supply. We will not be able to remove units from bidders that were already clinched in previous rounds.

\section{Designing the GA for the bidding strategy}

GAs have been proven to be powerful method to search non-linear problems for good solutions in many domains (Mitchell, 1996). The aim of our GA is to find a set of bidding rules that maximize the payoff of a bidder according to equation (1). To this end we have defined several experimental environments for which each bidder has a different set of values and a specific bidding strategy.

\subsection{Defining the experimental environments}

The experiment employs an independent-private-value framework in which bidders have weakly diminishing marginal values, are risk neutral and have no budget constrains. All bidders except one have a fixed strategy which is SB. Bidders will reduce their demanded quantities just when the actual price is equal to their real values. On the other hand, the bids of the bidder who follows the GA strategy will depend on several actions that we will define as deviations from the SB strategy.

This behaviour is explored for several environments that differ in the following variables: the number of lots auctioned $m=10,15,20,25$; the number of bidders $n=4$, 6,8 and the elasticity of the bidders' demand curves. The elasticity of bidders' demand curve depends on their valuations of the items which are generated as we describe below.

Every bidder has a set of values organized from high to low that specify the marginal value from the consumption of each additional unit. In our model we force each bidder to define his values for at least as many items as the total supply. Bidders' values are drawn independently and identical distributed from a uniform distribution with support $[1,200]$, with new random draws for each additional unit. For the experiments with elastic demand curves and $p^{0}=10$, bidders' values are drawn in the interval $[11,200]$. With this requirement, the valuations are always higher than the starting price of the auction so, we ensure that the total supply is fully subscribed at the starting price and the auction do not failed. These values are generated with two different algorithms which gives us either elastic or inelastic demand curves.

The set of values that yields elastic demand curves are generated for every bidder in the following manner. The algorithm starts with a random number between 1 and 200 which is bidder $i$ valuation for the first unit $\left(v_{i, 1}\right)$. For each additional unit we reset the upper bound by lowering it at a fixed rate equal to 200 divided by the total number of 
units auctioned multiplied by two. The values for each unit are the minimum of a random number generated under the new bound and the value of the preceding unit. In the elastic demand curves, the quantities demanded by the bidders decrease quite quickly as the price goes up.

The bidders' values for the inelastic demand curves are generated as follows. The algorithm starts just like the previous computing $v_{i, 1}$ which is a random number between 1 and 200. Once we have the value of the first unit we generate a random number between 1 and that value. The value assigned to the next unit would be the maximum of that random number and the value of the previous unit divided by two. In the elastic demand curves, the quantities demanded by the bidders don't decrease significantly as price goes up.

With these two algorithms we generate the values that every bidder has for each item to be auctioned, which will determine the bidding strategy for all participants.

\subsection{Bidding strategy}

In each auction all bidder are programmed to bid the equilibrium bidding strategy, i.e. their true value. There is only one bidder that has to beat his computer rivals by following the GA bidding strategy. The definition of the GA strategy that we suggest requires the identification of actions linked to specific auction conditions. Each action is defined in terms of deviations (over and underbidding) from the SB strategy. The demanded quantity according to the SB strategy of bidder $i$ in the round $l$ is represented by $q_{S B i}^{l}$. To this end we consider the following four possible actions to be taken: bid half of the SB quantity $\left(q_{S B i}^{l} / 2\right)$; bid the SB quantity $\left(q_{S B i}^{l}\right)$; bid $50 \%$ more of the SB quantity $\left(q_{S B i}^{l} * 1.5\right)$ or bid twice as much as the SB quantity $\left(q_{S B i}^{l} * 2\right)$, see table 2 . The bidder that evolves with the GA strategy will bid one of these four actions according to the auction condition of each round. All these strategies have an upper bound that is the lowest of either the number of units being auctioned or, alternatively, the units demanded in the previous round (as demand is required to be non increasing). The lower bound is the number of units that the participant has already clinched.

\begin{tabular}{lll} 
Bidding strategy & $\begin{array}{l}\text { Quantity } \\
\text { demanded }\end{array}$ & Code \\
\hline bid half of the SB & $q_{S B i}^{l} / 2$ & 00 \\
bid the SB & $q_{S B i}^{l} * 1.5$ & 01 \\
bid 50\% more of the SB & $q_{S B i}^{l} * 10$ \\
bid twice as much as the & $q_{S B i}^{l} * 2$ & 11 \\
\hline
\end{tabular}

Table 2: Each bidder considers four possible actions for each auction condition

Bidders face 61 possible auction conditions. The first one represents the initial market where no relevant information is available. To define the others 60 possible auction conditions we make up a combination of the potential values of three different indicators. In each auction the value of theses indicators change form one round to another. As our auction format has dropout information, the bidder that follows the GA strategy constantly calculates theses indicators and select the appropriate action or bid. These indicators are described as follows and are represented in table 3 .

The first one is the trend of price elasticity of demand from the competitors $\left(\varepsilon_{p, d}\right)$. This is the evolution of the competing bidders sensitivity of demand according to price increases. Formally, the definition of price elasticity of demand responds to equation (6).

$$
\varepsilon_{p, q}=\frac{\frac{Q^{l-1}-Q^{l-2}}{Q^{l-2}}}{\frac{p^{l-1}-p^{l-2}}{p^{l-2}}}
$$

Where $p^{l-1}$ denotes the price at the $(l-1)$ round on which one or more bidders strictly decreased the quantity demanded, and $Q^{l-1}$ denotes the sum of the quantities demanded by bidders $1, \ldots, n$ at round $(l-1)$. In the same way, the indexes $(l-2)$ refer to the previous round.

Since we are concerned with the evolution of this value the magnitude that we consider is the ratio of the mentioned elasticity divided by the same elasticity in which we consider ( $(-2)$ and ( $(-3)$ data. These ratios are classified into five categories: $\geq 1.5 ;<1.5 ;=1 ;<1$ and $<0.5$.

The second indicator is the percentage of active bidders $(\mathrm{AB} \%)$. This is the number of bidders that ask for at least one unit at that round over the number of bidders at the beginning of the auction. We have classified this indicator in three categories: $<100 \% ;<50 \%$ and $<25 \%$.

The third indicator is the operating margin of the strategic bidder (OM). This variable is defined as the ratio of the total number of units that no one clinched in the previous round over the number of units demanded by the bidder using the GA strategy in that previous round. This indicator is also classified into four categories: $\geq 2 ;<2$; $<1.25$ and $<1$

$$
\begin{aligned}
& \frac{\varepsilon_{p, d}}{\geq 1.5}+\frac{\mathrm{AB}(\%)}{<100 \%}+\frac{\mathrm{OM}}{\geq 2}+\begin{array}{l}
<50 \% \\
<1.5
\end{array}+\text { Initial }=61
\end{aligned}
$$

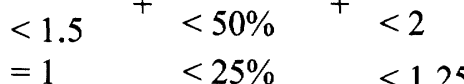

$$
\begin{aligned}
& <1<1 \\
& >0.5
\end{aligned}
$$

\subsection{Genetic Algorithm}

The encoding of the bidding strategies to the individuals is a direct process. As we mentioned before, all strategies consist of a set of 61 integers valued from 0 to 3 , depending on the action to be taken which depends on the auction conditions. Since the actions can be encoded in 2 bits each strategy could be represented as an array of 122 bits. This includes the SB strategy. Since we define the action of following the SB strategy as $1(01)$, the strategy of a SB bidder would be represented as a string of 122 bits (where the value of every odd bit is 0 and 1 otherwise). 
The assessment of a bidding strategy is made by running an auction twice. In the first run all bidders fulfil SB. In the second one, we let one bidder (bidder 1) evolve according to the GA and the others follow SB. Once we have the allocations and payments for each bidder, we calculate for both runs the payoff for the strategic bidder according to equation (1). The GA strategy will success as higher the payoff for bidder 1 is in the second run rather than in the first one, no matter what the others bidders payoff or the sellers revenue.

The search for the best strategy for each environment was performed using populations of 30 individuals that evolved for 1,000 generations. The GA used elitism, a roulette wheel selection mechanism in addition to mutation and single-point crossover probabilities of 0.9 and 0.01 respectively.

\section{Evaluating the bidding strategy}

In this section we evaluate the outcome obtained by the GA strategy. We have run the experiments for all the environments described in section 2. For each environment we ran the algorithm 25 times thus letting a population of 30 individuals evolve for 1,000 generations. To evaluate the GA strategy we compare the payoff of the GA bidder with what he would have obtained with the SB strategy, table 4. The results show that the GA outperforms the SB strategy in all the experiments except in one, as the bidders' payoff is always higher with the GA strategy than with the SB one. This reveals that, at least in some cases, bidders' payoff can be improved by using our GA strategy rather the SB one. Moreover, we compute the differences of the bidders profits with the GA and SB and averaged across auction within each value of $\mathrm{m}$. This variable is significantly and positive correlated at the level of $1 \%$ with the number of lots auctions ( $r=0.157$, $p=0.000$ ), what suggests that as $\mathrm{m}$ increases the GA has more chances to beat the SB strategy.

\begin{tabular}{crrrrr}
\cline { 3 - 5 } & & $m=10$ & $m=15$ & $m=20$ & $m=25$ \\
\cline { 3 - 5 } Elastic & & & & \\
\cline { 1 - 3 }$n=4$ & & 0.16 & 1.40 & 18.98 & 7.36 \\
$n=6$ & & 1.60 & 0.32 & 0.08 & 0.00 \\
$n=8$ & & 0.24 & 1.32 & 0.68 & 0.64 \\
Inelastic & & & & & \\
\cline { 1 - 1 }$n=4$ & & 0.60 & 0.84 & 0.64 & 1.08 \\
$n=6$ & & 0.40 & 0.40 & 0.44 & 0.80 \\
$n=8$ & 1.36 & 0.12 & 0.08 & 1.60 \\
\hline
\end{tabular}

Table 4: Payoff average difference for SB and GA bidding strategies

The key point in this research is to find out what is the bidding strategy of the GA that outperforms the SB. To this end we have analysed in detail the process of six different auctions (three of them with elastic demand curves and the others inelastic) for $n=4$ and $m=15$ in which the GA beats the SB strategy. Appendix A includes the auction process for one of this examples Moreover, with this analysis we verify that both, the auction process simulator and the GA, work properly.

When we compare the GA strategy of bidder 1 respect to the SB we can observe that at the beginning of the auction the participant is overbidding. Particularly, in this example, his action or bid is equal to $q_{S B i}^{l} * 2$ (code 11), i.e., his is bidding 12 when $q_{S B i}^{l}$ is 6 . He continues overbidding just until he determines the best moment to underbid and push the auction to rationing. There are two main facts that affect this decision. i) The demand of the others competitors $\left(q_{2}^{l}+q_{3}^{l}+q_{4}^{l}\right)$ plus what he has already clinched $\left(C_{l}\right)$ is equal to $M$, equation (7). ii) What he has already clinched plus the items not sold jet divided by the number of active bidders $(A B)$ is equal to $q_{S B i}^{l}$, equation (8).

$$
\begin{gathered}
\sum_{j \neq 1} q_{j}^{l}+C_{1}^{l}=M \\
C^{l}{ }_{1}+\left(\frac{M-\sum_{i=1}^{n} C_{i}^{l}}{A B}\right)=q_{S B 1}^{l}
\end{gathered}
$$

When equation (7) holds, this implies that the excess demand of the auction is equal to bidder $i$ bid minus what he has already clinch, $Q^{l}-M=q_{1}^{l}-C_{1}^{l}$. Therefore, by underbidding in the next round, he has a high probability of pushing the auction to a rationing situation. The strategic bidder will also calculate the number of items that he will get if the rationing rule is put into effect in that round, equation (8). When what he has clinched plus what he will probably get with the rationing rule is equal to $q_{S B i}^{l}$, then it would be the moment to underbid.

At that point the best strategy for bidder 1, according to the GA, is to make his possible minimum bid in the next round, i. e., $q_{1}^{L}=C_{1}^{L-1}$. In this example he bids 3 when $q_{S B i}^{l}$ is 6 , so his action is $q_{S B i}^{l} * 1 / 2$ (code 00 ), the participant is underbidding. By doing this, bidder 1 push the auction to rationing.

In this example, when the auction runs for the first time, the final allocation of the items according to the clinching rules is: $C_{1}^{L}=5, C_{2}^{L}=3, C_{3}^{L}=3$ and $C_{4}^{L}=4$. Nevertheless, the allocation in the second run when bidder 1 bids according to the GA is: $C_{1}^{L}=6, C_{2}^{L}=3, C_{3}^{L}=3$ and $C^{L}{ }_{4}=3$. As a consequence of the GA strategy, when rationing rule is applied, bidder 1 gets one additional units (the $6^{\text {th }}$ ). His personal value for this unit is $v_{1,6}=20$. In the other hand, bidder 4 has lost his $4^{\text {th }}$ item, which had a value of: $v_{4,4}=27$. As we can see, if bidder 1 behaves according to the GA and this particular rationing rule is applied, efficiency is no longer guarantee, as the bidder with the highest valuation is not necessarily the one that 
wins the object.

In the others examples the bidder with the GA strategy has very similar pattern to what we have seen. He starts overbidding until the GA finds the optimal round to push the auction to rationing according to the probability to force rationing and his final allocation of items respect to his real valuations. At that moment he underbids by making the next bid equal to $q_{1}^{L}=C_{1}^{L-1}$ (his minimum possible bid).

With the specific rationing rule assumed, we have analysed the effect of the GA strategy over all the participants involve, table 5 . In the six examples that concerns us bidder 1 is always better off by following the GA bidding strategy rather than the SB. He always win, at least, the same number of objects and at a lower average price. In the other hand, the seller is always worst off as he does sell all the items but at a lower price. Hence his revenues are lower. The final outcome for the others participants depends on each specific auction. Sometimes they do also have higher payoff as the average selling price of the items is lower. Nevertheless, their payoffs can also be reduce form the fact that sometimes bidder 1 takes advantage of the rationing rule.

\begin{tabular}{lrrr} 
& $\begin{array}{c}\text { Payoff GA- } \\
\text { Payoff SB } \\
\text { bidder 1 }\end{array}$ & $\begin{array}{c}\text { Payoff GA- } \\
\text { Payoff SB } i \neq 1\end{array}$ & $\begin{array}{c}\text { Seller's revenue } \\
\text { GA- Seller's } \\
\text { revenue SB }\end{array}$ \\
\hline $\begin{array}{l}\text { Elastic demand curves } \\
\text { Example 1 }\end{array}$ & 73 & -27 & -59 \\
Example 2 & 20 & 12 & -40 \\
Example 3 & 6 & -10 & -1 \\
Inelastic demand curves & & -6 & -15 \\
Example 4 & 8 & 14 & -32 \\
Example 5 & 11 & 14 & -25 \\
Example 6 & 9 & \\
\hline \multicolumn{4}{c}{ Table 5:Effect of the GA strategy respect to the SB one for all } \\
\multicolumn{4}{r}{ participants with the SRR }
\end{tabular}

\section{Conclusions}

This computational experiment is focus on an specific dynamic ascending multi-unit auction with implementation of Vickrey pricing, which is referred as the Ausubel auction. We employ an independent-privatevalue framework with dropout information in which bidders have weakly diminishing marginal values. With these assumptions, in the Ausubel auction SB by every bidder constitutes an efficient equilibrium.

We have develop a GA that can be successfully employed to evolve bidding strategies for this auction format. The algorithm generates different bidding strategies or actions to be taken according to the auctions conditions which are defined by three indicators: tendency towards elasticity in price demand; the number of bidders active in the auction with respect to the bidders at the beginning of the auction; and the number of objects that have not been clinched with respect to the number of objects demanded by the GA bidder.

By relating the GA strategy to a specific bidder we have been able to compare the payoff to what he would have obtain with SB. We have run the experiments with two different demand curves: elastic and inelastic. The experiments were conducted separately for different numbers of bidders $(n=4,6,8)$ and objects auctioned $(m=10,15,20$, and 25). For each environment we ran the algorithm 25 times which allowed a population of 30 individuals to evolve for 1,000 generations.

The evaluation of the GA strategy reveals that the algorithm outperforms the SB strategy as the bidder payoff is always equal to or higher than with the SB strategy. To have a better understanding of the behaviour of the GA bidder we have analysed in depth the auction process of six examples where the GA beats the SB. In this analysis we found that the optimal bidding strategy that the GA propose for bidder 1 is to overbid just until the GA finds the optimal round to push the auction to rationing (according to the probability to force rationing and his final allocation of items respect to his real valuations). At that point the bidder will underbid by making his lower possible bid, i.e., what he has already clinch $\left(q_{1}{ }^{L}=C_{1}^{L-1}\right)$. With this performance he maximizes his payoff. In all the auctions analysed bidder 1 is always better off, the seller is always worst off and the outcome of the other participants will depend on each specific auction.

These results reveal that the implementation of GAs and the selection of a rationing rule can be a key point in the final outcome of an Ausubel auction, both in allocations and payments. Some authors have already studied the importance of the rationing rule to establish the existence of an equilibrium in many games, including auctions, see Jackson, Simon, Swinkels \& Zame (2002). Nevertheless there is not much done about GAs and auctions, hence it could be an interesting line of future research.

\section{Bibliography}

Andreoni J., Miller J.H. (1995) "Auctions with Artificial Adaptive Agents," Games and Economic Behaviour, 10, 39-64.

Anthony, P., Jennings, N.R. (2002) "Evolving Bidding Strategies for Multiple Auctions," Proceedings of the $15^{\text {th }}$ European Conference on Artificial Intelligence. 178-182.

Anthony, P., Jennings, N.R. (2003) "Developing a Bidding Agent for Multiple Heterogeneous Auctions," ACM Transactions on Internet Technology. 3 (3), 185217.

Arifovic, J. (1994) "Genetic algorithms learning and the cobweb model," Journal of Economic Dynamics and Control. 18 (1), 3-28.

Arifovic, J. (1995) "Genetic algorithms and inflationary economies," Journal of Monetary Economics. 36, 219243.

Arifovic, J. (1996) "The behaviour of exchange rate in the genetic algorithm and experimental economies," Journal of Political Economy. 104, 510-541. 
Arifovic, J. \& Gencay, R. (2000) "Statistical Properties of Genetic Algorithm Learning in Macroeconomic Models," Journal of Economic Dynamics and Control. 24, 9811005

Ausubel, L.M. (1997) "An Efficient Ascending-Bid Auction for Multiple Objects," University of Maryland. Working Paper No. 97-06.

Ausubel, L.M. (2004) "An Efficient Ascending-Bid Auction for Multiple Objects," American Economic Review, 94, 1452-1475.

Axelrod, R. 1987. The evolution of strategies in the iterated Prisoner's Dilemma, in Genetic Algorithms and Simulated Annealing. L. Davis (ed.), London: Pittman. $32-41$.

Bikhchandani, S. and Ostroy, J.M. (2005) "Ascending price Vickrey auctions," Games and Economic Behaviour, Article in press.

Bremermann, H. (1962). "Optimization through evolution and recombination." In Yovits, M., Jacobi, G. T., and Goldstine, G., editors, Self-Organizing Systems. Spartan Books, Washington DC, 93-106.

Cliff, D. (2003) "Exploration in evolutionary design of online auction market mechanisms," Electronic Commerce Research and Applications. 2 (2) 162-175.

Dawid, H. (1996) "Learning of cycles and sunspot equilibria by genetic algorithms," Journal of Evolutionary Economics. 6, 361-373.

Dawid, H. (1999) "On the convergence of genetic learning in a double auction market" Journal of Economic Dynamics \& Control. 23, 1545-1567.

Dawid, H. and Kopel, M. (1998) "On Economic Applications of the Genetic Algorithm: A Model of the Cobweb Type" Journal of Evolutionary Economics. 8 (3), 297-315.

Fraser, A.S. (1957) "Simulation of genetic systems by automatic digital computers II. Effects of linkage on rates under selection." Australian J. of Biol Sci, vol 10, 492499.

Holland, J. (1975) "Adaptation in Natural and Artificial Systems”, Ann Arbor. University of Michigan Press.

Jackson, M. O. Simon, L. K. Swinkels J. M. and Zame W. R.. (2002) "Communication and Equilibrium in Discontinuous Games of Incomplete Information," Econometrica 70, 1711-1740

Kagel, J.H. Kinross, S. Levin D., (2004) "Implementing efficient multi-object auctions institutions: an experimental study of the performance of boundedly rational agents". OSU Working paper 11/04.

Kagel J.H. and Roth A.E. (1995) "Auctions: A Survey of Experimental Research," in The Handbook of Experimental Economics, Princeton University Press.

Kagel, J.H. Ye, L and Pevnitska, S. (2004) "Survival auctions". Econometric Society 2004 North American Winter Meetings. $N^{\circ} 414$.

Klemperer, P. (1999) "Auction Theory: a Guide to Literature," Journal of Economics Survey, 13 (3), 227 286.

Klemperer, P. (2000a) "The Economic Theory of Auctions. Volume I," Cheltenham, UK: Edward Elgar.

Klemperer, P. (200b) "The Economic Theory of Auctions. Volume II" Cheltenham, UK: Edward Elgar.

Klemperer, P. (2003) "Auctions: Theory and Practice," Princeton University Press.

Krishna, V. (2002) "Auction Theory," San Diego: Academic Press.

Laffont, J.J. (1997) "Game theory and empirical economics: the case of auction data," European Economic Review. 41, 1-35.

Manelli, A. Sefton, M. Wilner, B. (2000) "Multi-unit auctions: a comparison of static and dynamic mechanisms," Conference on applied research concerning auctions and mechanism design. University of Iowa.

McAfee R.P. and Mc Millan J. (1987) "Auctions and bidding,” Journal Economic Literature. 699-738.

Milgrom, P. (2004) "Putting Auction Theory to Work," Cambridge University Press.

Miller, J.H. (1986) "A Genetic Model of Adaptive Economic Behaviour," University of Michigan working paper.

Miller, J.H. (1996) "The Coevolution of Automata in the Repeated Prisoner's Dilemma," Journal of Economic Behaviour and Organization. 29 (1). 87-112.

Mitchell, M.: 1996, “An introduction to genetic algorithms", MIT Press.

Numnonda, T and Annakkage, U. D. (1999) "Optimal power dispatch in multimode electricity market using genetic algorithm," Electric Power Systems Research. 49 (3). 211-220. 
Routledge, B.R. (1995) "Artificial selection: genetic algorithm and learning in a rational expectation model," Manuscript, University of British Columbia, Vancouver. Sunnevag, K. J. (2001) "Auction design for the allocation of emission permits," Working Paper 5-01, UCSB.

Vickrey, W. (1961) "Counterspeculation, auctions and competitive sealed tenders," Journal of Finance. XVI. 837.

Wen, F.S and David, A.K. (2001) "Strategic bidding for electricity supply in a day-ahead energy market," Electric Power Systems Research. 59 (3), 197-206

\section{Apendix A:}

An example of an auction process where the GA beats the SB strategy

Bidders' values for $m=15$ and $n=4$

$$
\begin{aligned}
& v_{l, k}: 18291814135201053222111 \\
& v_{2, k}: 1005025221512632111111 \\
& v_{3, k}: 100503317168442111111 \\
& v_{4, k}: 106764427147421111111
\end{aligned}
$$

Auction process with SB strategy: $1^{\text {st }}$ column: current price $(p) ; 2^{\text {nd }}$ column: aggregate demand $\left(Q^{l}\right)$; other columns: quantities demanded $\left(q_{i}\right)$ and cumulative quantities clinched $\left(C_{i}\right)$ by Bidder 1 (B1),Bidder $2(\mathrm{~B} 2)$, Bidder 3 (B3) and Bidder 4 (B4) respectively.

\begin{tabular}{|r|r|r|r|r|r|r|r|r|r|}
\hline $\boldsymbol{p}$ & \multicolumn{1}{|c|}{$\boldsymbol{Q}^{l}$} & $\boldsymbol{q}_{1}$ & $\boldsymbol{C}_{\boldsymbol{1}}$ & $\boldsymbol{q}_{2}$ & $\boldsymbol{C}_{2}$ & $\boldsymbol{q}_{3}$ & $\boldsymbol{C}_{3}$ & $\boldsymbol{q}_{4}$ & $\boldsymbol{C}_{4}$ \\
\hline 10 & 22 & 6 & 0 & 6 & 0 & 5 & 0 & 5 & 0 \\
\hline 12 & 21 & 6 & 0 & 5 & 0 & 5 & 0 & 5 & 0 \\
\hline 14 & 20 & 6 & 1 & 5 & 0 & 5 & 0 & 4 & 0 \\
\hline 15 & 19 & 6 & 2 & 4 & 0 & 5 & 1 & 4 & 0 \\
\hline 16 & 18 & 6 & 3 & 4 & 1 & 4 & 1 & 4 & 1 \\
\hline 17 & 17 & 6 & 4 & 4 & 2 & 3 & 1 & 4 & 2 \\
\hline 20 & 16 & 5 & 4 & 4 & 3 & 3 & 2 & 4 & 3 \\
\hline 22 & 15 & 5 & 5 & 3 & 3 & 3 & 3 & 4 & 4 \\
\hline
\end{tabular}

Table 6: Example 1: Auction process with all bidders SB strategy

Auction result with SB:

Prices at which bidders clinched each item:

$B 1: 14151617$ 22; B2: 1617 20; B3: 1520 22; B4: 16172022

\section{Payoff B1: 346}

Auction process with GA strategy: $1^{\text {st }}$ column: current price $(p) ; 2^{\text {nd }}$ column: aggregate demand $\left(Q^{l}\right)$; other columns: quantities demanded $\left(q_{i}\right)$ and cumulative quantities clinched $\left(C_{i}\right)$ by Bidder 1 (B1),Bidder 2 (B2), Bidder 3 (B3) and Bidder 4 (B4) respectively.

\begin{tabular}{|c|c|c|c|c|c|c|c|c|c|}
\hline$p$ & $\boldsymbol{Q}^{I}$ & $\boldsymbol{q}_{1}$ & $\boldsymbol{C}_{\boldsymbol{1}}$ & $\boldsymbol{q}_{\mathbf{2}}$ & $\boldsymbol{C}_{2}$ & $\boldsymbol{q}_{3}$ & $\boldsymbol{C}_{3}$ & $\boldsymbol{q}_{4}$ & $\boldsymbol{C}_{\mathbf{4}}$ \\
\hline 10 & 28 & 12 & 0 & 6 & 0 & 5 & 0 & 5 & 0 \\
\hline 12 & 27 & 12 & 0 & 5 & 0 & 5 & 0 & 5 & 0 \\
\hline 14 & 26 & 12 & 1 & 5 & 0 & 5 & 0 & 4 & 0 \\
\hline 15 & 25 & 12 & 2 & 4 & 0 & 5 & 0 & 4 & 0 \\
\hline 16 & 24 & 12 & 3 & 4 & 0 & 4 & 0 & 4 & 0 \\
\hline 17 & 14 & 3 & 6 & 4 & 3 & 3 & 3 & 4 & 3 \\
\hline
\end{tabular}

Table 7: Example 1: Auction process with bidder 1 GA strategy

Auction result with bidder 1: GA and the others bidders: SB:

Prices at which bidders clinched each item:

$B 1: 1415161616$ 16; B2: 1616 16; B3: 161616 ; $B 4: 161616$

Payoff $B 1: 357$ 